\title{
The Complete Nucleotide Sequence of the Domestic Dog (Canis familiaris) Mitochondrial Genome
}

\author{
Kyung Seok Kim, Seong Eun Lee, Ho Won Jeong, and J i Hong $\mathrm{Ha}^{1}$ \\ Department of Genetic Engineering, Kyungpook National University, Taegu City 702-701, Korea
}

Received September 12, 1997; revised December 8, 1997

The complete nucleotide sequence of the mitochondrial genome of the domestic dog, Canis familiaris, was determined. The length of the sequence was 16,728 bp; however, the length was not absolute due to the variation (heteroplasmy) caused by differing numbers of the repetitive motif, 5'-GTACACGT(A/G)C-3', in the control region. The genome organization, gene contents, and codon usage conformed to those of other mammalian mitochondrial genomes. Although its features were unknown, the "CTAGA" duplication event which followed the translational stop codon of the COII gene was not observed in other mammalian mitochondrial genomes. In order to determine the possible differences between mtDNAs in carnivores, two rRNA and 13 protein-coding genes from the cat, dog, and seal were compared. The combined molecular differences, in two rRNA genes as well as in the inferred amino acid sequences of the mitochondrial 13 protein-coding genes, suggested that there is a closer relationship between the dog and the seal than there is between either of these species and the cat. Based on the molecular differences of the mtDNA, the evolutionary divergence between the cat, the dog, and the seal was dated to approximately $\mathbf{5 0} \pm \mathbf{4}$ million years ago. The degree of difference between carnivore mtDNAs varied according to the individual protein-coding gene applied, showing that the evolutionary relationships of distantly related species should be presented in an extended study based on ample sequence data like completemtDNA molecules.

Key Words: mitochondrial genome; complete nucleotide sequence; evolutionary relationships; Carnivora; dog; seal; cat.

\section{INTRODUCTION}

The size (16 $17.5 \mathrm{~kb})$, gene constituents ( 22 tRNA, 2 rRNA, and 13 protein-coding genes), and genomic

\footnotetext{
${ }^{1}$ To whom correspondence should be addressed at Department of Genetic Engineering, College of Natural Sciences, Kyungpook National University, 1370 Sankyuk-dong, Puk-gu, Taegu 702-701, Korea. Fax: (+82) 53-943-6925. E-mail: jhha@bh.kyungpook.ac.kr.
}

organization of mammalian mitochondrial DNA (mtDNA) are becoming well characterized. In all mammalian species the mitochondrial genomes reveal an overall conservation of gene order and a very compact organization of genetic information (Anderson et al., 1981; Attardi, 1985; J anke et al., 1994). The mtDNA of most animals is maternally inherited without recombination and evolves rapidly (Roy et al., 1994). The rate of nucleotide substitution in mitochondrial genomes is 10 times greater than that in nuclear genomes, which is presumably due to a reduced fidelity of mtDNA replication and DNA repair, and due to the high levels of oxygen radicals in the electron transport process. The relatively high rate of evolution of mitochondrial genes makes mtDNA sequence comparisons especially useful for estimating the dates of relatively recent evolutionary events as well as the evolution of distantly related taxa.

To date, the complete nucleotide sequences of mitochondrial genomes of 19 mammalian species have been published (human, mouse, cow, rat, fin whale, blue whale, harbor seal, grey seal, horse, American opossum, hedgehog, gorilla, common and pygmy chimpanzee, Bornean orangutan, Sumatran orangutan, Indian rhinoceros, donkey, platypus, guinea pig, cat, white rhinoceros, wallaroo, and armadillo) (Anderson et al., 1981, 1982; Bibb et al., 1981; Gadaleta et al., 1989; Arnason et al., 1991, 1993; Arnason and J ohnsson, 1992; Arnason and Gullberg, 1993; Xu and Arnason, 1994; J anke et al., 1994; Krettek et al., 1995; Horai et al., 1995; Xu and Arnason, 1996; Xu et al., 1996a,b; J anke et al., 1996; D'Erchia et al., 1996; Lopez et al., 1996; Xu and Arnason, 1997; J anke et al., 1997; Arnason et al., 1997). These mammalian mtDNA data have contributed to the study of molecular dynamics, the evolution of genomes, mammalian phylogeny, and comparative genetics (Kocher et al., 1989; Li and Graur, 1991; Charlesworth et al., 1994; O'Brien, 1994a,b; Pecon et al., 1994; Avise, 1994; Morin et al., 1994; D'Erchia et al., 1996; Penny and Hasegawa, 1997). The partial comparisons of mtDNA at the population and species level have been used to estimate the evolutionary divergence times of the human, primate, white 
sturgeon, feline, and canine species (Aquadro and Greenberg, 1983; Ramharack and Deeley, 1987; Ruvulo et al., 1993; Brown et al., 1993; J anczewski et al., 1995; Vila et al., 1997). Nevertheless, the use of complete mtDNAs is essential for comparison because it has been shown that individual mtDNA genes may provide different answers to phylogenetic questions (Arnason and J ohnsson, 1992; Cao et al., 1994; Xu et al., 1996a; Xu and Arnason, 1996). In recent years, phylogenetic analyses based on a concatenated sequence of the inferred amino acid sequence of protein-coding mtDNA genes (Cao et al ., 1994; K rettek et al., 1995; D'Erchia et al., 1996; Xu et al., 1996b; J anke et al., 1996, 1997; Penny and Hasegawa, 1997; Arnason et al ., 1997) made it possibleto establish phylogenetic relationships among seven mammalian orders: Primates (human, chimpanzee, gorilla, orangutan, and gibbon), Artidodactyla (cow), Cetacea (whale), Carnivora (seal and cat), Rodentia (mouse and rat), Perissodactyla (horse and rhinoceros), and Marsupialia (opossum and wallaroo). The overall evidence of the above phylogenetic relationship suggested that Marsupialia and Monotremata are an outgroup to the eutherians (J anke et al., 1996, 1997). The insectivores represent an earlier branch among eutherian orders (K rettek et al., 1995) and rodents are consistently found basal to primates and ferungulates. Carnivora are joined with Perissodactyla (Xu et al., 1996b), and Ferungulata contains all these orders including now the Cetacea (J anke et al., 1994, 1997) as a sistergroup to Artidodactyla. As such, the complete sequence comparisons of mammalian mtDNAs have contributed to the documentation of a reliable phylogenetic relationship among mammals. However, although the phylogenetic relationship among mammalian orders seems to be firmly established, there remains an uncertainty concerning the relationships within the order, especially between carnivores (cat, dog, and seal). The main split within Carnivora is that between Feliodea (cats) and Canoidea (dogs and seals) as has been proposed by morphological data. However, it was difficult to demonstrate this basic split by molecular data. The comparisons within Carnivora at the level of the entire mtDNA molecule have so far been limited by paucity of data. Moreover, the phylogenetic position of the Canidae relative to other mammalian orders is still unsettled. Until now the complete mtDN A sequences of only three carnivore species (Phoca vitulina, Halichoerus grypus, and F elis catus) have been reported (Arnason and J ohnsson, 1992; Arnason et al., 1993; L opez et al., 1996).

In the present study we report on the first complete nucl eotide sequence of the mitochondrial genome of the domestic dog, Canis familiaris, and compare it with the mtDNAs of other carnivore species (the cat and two species of seal). We also propose a dating of the evolutionary divergence between the cat, the dog, and the seal from the comparison of the mtDNAs. The addition of the dog mtDNA to previously reported carnivore mtDNAs will contribute to a further understanding of the evolutionary relationships within this group.

\section{MATERIALS AND METHODS}

MtDNA was isolated from the liver of a Korean native dog, Sapsaree, according to Zimmerman's method (1988) and purified by cesium chloride ultracentrifugation (Lansman et al., 1981). The entire mtDNA was recovered in four Apal fragments (7.0, 4.8, 3.7, and 1.2 $\mathrm{kbp}$ ) and cloned into the plasmid pGEM vector. Each cloned fragment was further digested with BamHI, HindlII, EcoRI, or Xbal and subcloned into plasmids pGEM5Zf or pGEM7Zf. The entire mtDNA molecule was covered by natural (not PCR) clones. The mtDNA sequence was determined manually by polyacrylamide gel electrophoresis using the dideoxynucleotide chain termination method (Sanger et al., 1977) with [ ${ }^{35}$ S]dATP. Sequencing was carried out using both universal and numerous synthetic oligonucleotide primers. For complete sequencing, deletion mutants were constructed with intervals of about 200 bp according to the manufacturer's protocol (Erase-a-Base system, Promega). The entire DNA sequences were determined from both strands. Sequences that contained any ambiguous or unreadable nucleotides were sequenced again with synthetic internal primers.

The mtDNA sequences, inferred amino acid sequences, and secondary structure of the ribosomal and transfer RNAs were analyzed using the PC/GENE software program (Bairoch, 1992). The pairwise comparisons of two rRNA and 13 protein-coding genes from the carnivore species were performed with the previously determined mtDNAs retrieved from the GenBank database (Accession No. U20753 for the cat, X72004 for the grey seal, and X63726 for the harbor seal). In all comparisons, the rRNA genes or proteincoding genes of the cat and dog were compared with both the harbor seal and the grey seal and then the values were averaged.

The complete mtDNA sequence of the dog, C. familiaris, was deposited in the GenBank database under Accession No. U96639.

\section{RESULTS}

\section{Composition and Organization of Dog mtDNA}

The length of the mtDNA molecule of the dog, C. familiaris, was $16,728 \mathrm{bp}$, having a control region 1270 bp long including 30 tandem repeats of a 10-nt motif between conserved sequence block (CSB) I and II. Complete sequencing relied on the universal primers supplemented with 20 specific internal primers, 17 subclones, and 42 deletion mutants. The organization 
and direction of 13 open reading frames, 22 tRNA genes, two rRNA genes (12S and 16S rRNA), and the regulatory control region were the same as those in other mammalian species studied previously. The total base compositions of the L-strand were: $A, 31.6 \%$; $C$, 25.5\%; G, 14.1\%; and T, 28.8\%. This composition of dog mtDNA exhibited a higher dT content than that of the seal and cat mtDNAs (Arnason and J ohnsson, 1992; Lopez et al., 1996). Also, similar to the seal and cat mtDNAs, the dog mitochondrial genome exhibited a higher overall dG content among mammals showing that $\mathrm{dA}$ or $\mathrm{dC}$ have converged into dG or dT. Characteristics of the dog mitochondrial genome are shown in Table 1 . The numbering system for the dog mtDNA followed the mouse and horse conventions (Bibb et al., 1981; Xu and Arnason, 1994), which allocated position one of those completed mtDNA sequences to the 5' terminus of the tRNA-Phe encoding gene. The limits and nomenclature of each gene were determined by comparison with other known mammalian mtDNAs. The site of origin of light strand replication (OLR) was located within a cluster of five tRNA genes (Table 1). Although the 37-bp length of the dog OLR was one base longer than that of other mammals, its features were highly conserved with other mammals and had a stable stem-loop structure (free energy: $-17.4 \mathrm{kcal} / \mathrm{mol}$ ), consisting of an 11-bp stem region with complete intrastrand complementarity and a 14-base loop region as in

TABLE 1

Characteristics of the Domestic Dog Mitochondrial Genome

\begin{tabular}{|c|c|c|c|c|c|}
\hline Gene & From $5^{\prime}$ to $3^{\prime}$ & Lengtha & Start codon & Stop codon & 5' Intervening spacer \\
\hline tRNA-Phe & $1-70$ & 70 & & & \\
\hline $12 S$ rRNA & $71-1,024$ & 954 & & & \\
\hline tRNA-Val & $1,025-1,091$ & 67 & & & \\
\hline 16S rRNA & $1,092-2,673$ & 1582 & & & \\
\hline tRNA-Leu (UUR) & $2,674-2,747$ & 74 & & & \\
\hline NADH dehydrogenase subunit 1 (ND1) & $2,750-3,706$ & 957 & ATG & TAA & AA \\
\hline tRNA-IIe & $3,706-3,774$ & 69 & & & \\
\hline tRNA-GIn & $3,845-3,771$ & $75 \mathrm{~L}$ & & & \\
\hline tRNA-Met & $3,847-3,916$ & 70 & & & C \\
\hline NADH dehydrogenase subunit 2 (ND2) & $3,917-4,960$ & 1044 & ATA & TAG & \\
\hline tRNA-Trp & $4,959-5,026$ & 68 & & & ATCAАATСАССТС \\
\hline tRNA-Ala & $5,108-5,040$ & $69 \mathrm{~L}$ & & & $\mathrm{C}$ \\
\hline tRNA-Asn & $5,181-5,110$ & $72 \mathrm{~L}$ & & & \\
\hline Origin of L-strand replication (OLR) & $5,182-5,218$ & 37 & & & \\
\hline tRNA-Cys & $5,282-5,215$ & $68 \mathrm{~L}$ & & & \\
\hline tRNA-Tyr & $5,350-5,283$ & $68 \mathrm{~L}$ & & & \\
\hline Cytochrome c oxidase subunit I (CO I) & $5,352-6,896$ & 1545 & ATG & TAA & $\mathrm{T}$ \\
\hline tRNA-Ser (UCN) & $6,964-6,894$ & $71 \mathrm{~L}$ & & & \\
\hline tRNA-Asp & $6,969-7,036$ & 68 & & & TCAG \\
\hline Cytochrome c oxidase subunit II (CO II) & $7,037-7,720$ & 684 & ATG & TAA & \\
\hline tRNA-Lys & $7,738-7,804$ & 67 & & & CCTAGACTAGATCTACT \\
\hline ATPase 8 & $7,806-8,009$ & 204 & ATG & TAA & A \\
\hline ATPase 6 & $7,967-8,647$ & 681 & ATG & TAA & \\
\hline Cytochrome c oxidase subunit III (CO III) & $8,647-9,430$ & 784 & ATG & Taac & \\
\hline tRNA-Gly & $9,431-9,498$ & 68 & & & \\
\hline NADH dehydrogenase subunit 3 (ND3) & $9,499-9,845$ & 347 & ATA & TAac & \\
\hline tRNA-Arg & $9,845-9,912$ & 68 & & & \\
\hline NADH dehydrogenase subunit 4L (ND4L) & $9,913-10,209$ & 297 & ATG & TAA & \\
\hline NADH dehydrogenase subunit 4 (ND4) & $10,203-11,580$ & 1378 & ATG & $\mathrm{Taac}^{\mathrm{C}}$ & \\
\hline tRNA-His & $11,579-11,649$ & 71 & & & \\
\hline tRNA-Ser (AGY) & $11,650-11,709$ & 60 & & & \\
\hline tRNA-Leu (CUN) & $11,710-11,779$ & 70 & & & \\
\hline NADH dehydrogenase subunit 5 (ND5) & $11,780-13,600$ & 1821 & ATA & TAA & \\
\hline NADH dehydrogenase subunit 6 (ND6) & $14,111-13,584$ & $528 \mathrm{~L}$ & ATG & TAA & \\
\hline tRNA-Glu & $14,179-14,110$ & $70 \mathrm{~L}$ & & & \\
\hline Cytochrome b & $14,184-15,323$ & 1140 & ATG & AGA & ATTA \\
\hline tRNA-Thr & $15,324-15,393$ & 70 & & & \\
\hline tRNA-Pro & $15,458-15,393$ & $66 \mathrm{~L}$ & & & \\
\hline Control region & $15,459-16,728$ & 1270 & & & \\
\hline
\end{tabular}

Note. Positions include the $5^{\prime}$ and $3^{\prime}$ nt of each gene. The numbering of positions starts with the $5^{\prime}$ position of tRNA-Phe.

a $L$ denotes light strand (sense).

b Denotes the $3^{\prime}$ intervening spacer of tRNA-Trp.

c Signifies an incomplete termination codon, and the lower case denotes a predicted codon after posttranscriptional polyadenylation. 
the OLR of the harbor seal. In this structure, the stem overlapped with tRNA-Cys gene by 4 nucl eotides.

\section{Protein-Coding Genes and Codon Usage}

The total number of the inferred amino acids from the 13 protein-coding genes of the dog mtDNA was 3792 , showing that this number was the same as that of the cat mtDNA but shorter than that of theseal mtDNA by 3 amino acids in the ni cotinamide adenine dinucleotide dehydrogenase (NADH) subunit 5 gene. As in other mammals, all protein coding genes except for the $\mathrm{NADH} 6$ gene are encoded on the $\mathrm{H}$-strand so that the $\mathrm{L}$-strand gives the sense reading frames. All proteincoding genes were oriented in the same direction, like their homologous counterparts found in other mammalian mtDNA. The pattern of codon usage in dog mtDNA followed the preference patterns reported in other mammalian mtDNA sequences (Table 2). However, compared to the cat and seal codon usage, the canine pattern shows an increase in CTT at the expense of CTA for Leu, an increase of TCT or TCG at the expense of TCA for Ser, and an increase of GCT or GCG at the expense of GCC for Ala. These differences can partially account for the higher content of $d G$ and $d T$ in the overall nucleotide composition of canine mtDNA. I nitiation codons (ATG or ATA) were the same as those of most other mammals. Regarding termination codons, the 11 genes usually used TAA. Of these, three genes had incompletetermination codons, which were presumably completed as TAA by posttranscriptional polyadenylation (Anderson et al., 1981). The NADH2 and cytochrome $b$ genes used TAG and AGA codons, respectively, as termination codons as in some other mammals. Also similar to other mammals, the coding sequences of the ATPase 8 and ATPase 6 , the NADH 4 and NADH4L, and the NADH5 and NADH 6 genes overlapped each other by 43,7 , and 17 nucleotides, respectively.

\section{tRNA and rRNA Genes}

The limits and directions of the dog tRNA genes were determined by alignment with those of other mammalian tRNA genes (Table 1). The combined length of the tRNA genes of the dog was 1519 nt, compared to 1507

TABLE 2

Total Codon Usage in the Dog Mitochondrial Genome

\begin{tabular}{|c|c|c|c|c|c|c|c|c|c|c|c|}
\hline \multirow[t]{2}{*}{ Phe } & TTT & $\begin{array}{c}107 \\
\left(108^{a} 68^{b}\right)\end{array}$ & Ser & TCT & $\begin{array}{c}68 \\
(33,35)\end{array}$ & Tyr & TAT & $\begin{array}{c}69 \\
(66,50)\end{array}$ & Cys & TGT & $\begin{array}{c}5 \\
(11.8)\end{array}$ \\
\hline & TTC & $\begin{array}{c}128 \\
(117,163)\end{array}$ & & TCC & $\begin{array}{c}75 \\
(73,74)\end{array}$ & & TAC & $\begin{array}{c}74 \\
(76,84)\end{array}$ & & TGC & $\begin{array}{c}22 \\
(14,16)\end{array}$ \\
\hline \multirow[t]{2}{*}{ Leu } & TTA & $\begin{array}{c}118 \\
(108,68)\end{array}$ & & TCA & $\begin{array}{c}78 \\
(112,106)\end{array}$ & Ter & TAA $^{c}$ & $\begin{array}{c}11 \\
(11,11)\end{array}$ & Trp & TGA & $\begin{array}{c}93 \\
(92,91)\end{array}$ \\
\hline & TTG & $\begin{array}{c}28 \\
(17,20)\end{array}$ & & TCG & $\begin{array}{c}13 \\
(8,10)\end{array}$ & & TAG & $\begin{array}{c}1 \\
(1,1)\end{array}$ & & TGG & $\begin{array}{c}10 \\
(12,13)\end{array}$ \\
\hline \multirow[t]{4}{*}{ Leu } & CTT & $\begin{array}{c}96 \\
(59,57)\end{array}$ & Pro & CCT & $\begin{array}{c}64 \\
(57,42)\end{array}$ & $\mathrm{His}$ & CAT & $\begin{array}{c}37 \\
(31,36)\end{array}$ & Arg & CGT & $\begin{array}{c}6 \\
(6,5)\end{array}$ \\
\hline & СТC & $\begin{array}{c}90 \\
(97,95)\end{array}$ & & CCC & $\begin{array}{c}62 \\
(59,81)\end{array}$ & & CAC & $\begin{array}{c}57 \\
(63,64)\end{array}$ & & CGC & $\begin{array}{c}10 \\
(9,13)\end{array}$ \\
\hline & CTA & $\begin{array}{c}230 \\
(273,297)\end{array}$ & & CCA & $\begin{array}{c}60 \\
(72,68)\end{array}$ & Gln & CAA & $\begin{array}{c}68 \\
(84,72)\end{array}$ & & CGA & $\begin{array}{c}45 \\
(45,43)\end{array}$ \\
\hline & CTG & $\begin{array}{c}33 \\
(42,58)\end{array}$ & & CCG & $\begin{array}{c}7 \\
(7,7)\end{array}$ & & CAG & $\begin{array}{c}21 \\
(7,14)\end{array}$ & & CGG & $\begin{array}{c}4 \\
(7,4)\end{array}$ \\
\hline \multirow[t]{2}{*}{ Ile } & ATT & $\begin{array}{c}175 \\
(151,131)\end{array}$ & Thr & ACT & $\begin{array}{c}75 \\
(72,51)\end{array}$ & Asn & AAT & $\begin{array}{c}66 \\
(56,40)\end{array}$ & Ser & AGT & $\begin{array}{c}18 \\
(18,17)\end{array}$ \\
\hline & ATC & $\begin{array}{c}167 \\
(179,203)\end{array}$ & & ACC & $\begin{array}{c}89 \\
(101,107)\end{array}$ & & AAC & $\begin{array}{c}91 \\
(94,107)\end{array}$ & & AGC & $\begin{array}{c}32 \\
(34,42)\end{array}$ \\
\hline \multirow[t]{2}{*}{ Met } & ATA & $\begin{array}{c}202 \\
(182,192)\end{array}$ & & ACA & $\begin{array}{c}120 \\
(124,137)\end{array}$ & Lys & AAA & $\begin{array}{c}80 \\
(89,89)\end{array}$ & & AGA & $\begin{array}{c}1 \\
(1,1)\end{array}$ \\
\hline & ATG & $\begin{array}{c}47 \\
(68,57)\end{array}$ & & ACG & $\begin{array}{c}17 \\
(14,22)\end{array}$ & & AAG & $\begin{array}{c}18 \\
(14,12)\end{array}$ & & AGG & $\begin{array}{c}0 \\
(0,0)\end{array}$ \\
\hline \multirow[t]{4}{*}{ Val } & GTT & $\begin{array}{c}50 \\
(33,56)\end{array}$ & Ala & GCT & $\begin{array}{c}63 \\
(51,46)\end{array}$ & Asp & GAT & $\begin{array}{c}28 \\
(29,26)\end{array}$ & Gly & GGT & $\begin{array}{c}45 \\
(33,26)\end{array}$ \\
\hline & GTC & $\begin{array}{c}27 \\
(38,44)\end{array}$ & & GCC & $\begin{array}{c}86 \\
(116,98)\end{array}$ & & GAC & $\begin{array}{c}41 \\
(39,46)\end{array}$ & & GGC & $\begin{array}{c}51 \\
(57,48)\end{array}$ \\
\hline & GTA & $\begin{array}{c}84 \\
(95,90)\end{array}$ & & GCA & $\begin{array}{c}88 \\
(84,100)\end{array}$ & Glu & GAA & $\begin{array}{c}72 \\
(76,74)\end{array}$ & & GGA & $\begin{array}{c}95 \\
(97,109)\end{array}$ \\
\hline & GTG & $\begin{array}{c}24 \\
(21,28)\end{array}$ & & GCG & $\begin{array}{c}14 \\
(8,8)\end{array}$ & & GAG & $\begin{array}{c}21 \\
(23,25)\end{array}$ & & GGG & $\begin{array}{c}28 \\
(30,22)\end{array}$ \\
\hline
\end{tabular}

a Indicates number of the total codon usage of the cat mitochondrial genome (Lopez et al., 1996).

b Indicates number of the total codon usage of the Harbor seal mitochondrial genome (Arnason and J ohnsson, 1992).

'Termination codons for COIII, ND3, and ND4 genes were included as TAA under the assumption that the posttranscriptional polyadenylation of the canine mRNAs for these genes was similar to that in other mammals. 
nt in the cat and 1510 nt in the seal. As in other mammals, 22 tRNA genes were found in the dog mtDNA, and had a similar organization. The small number of tRNA genes in the mammalian mtDNA is thought to be the result of strong pressure for the economization of the genome size (Anderson et al., 1981, 1982; Bibb et al., 1981; Clary and Wolstenholme, 1985; Wolstenholme et al., 1987; Gadaleta et al., 1989; Desjardins and M orais, 1990; Okimoto et al., 1992). The structural features of the dog mitochondrial tRNA molecules, such as the anticodon (AC) stem and loops, $\mathrm{T}-\Psi-\mathrm{C}$, and amino acid-acceptor (A-A) arms, showed an L-shaped tertiary structure identical to those found in other mammalian mitochondrial tRNA molecules (Cedegren et al., 1981; Kumazawa and Nishida, 1993). The tRNA-Ser-AGY, which was smallest in size, lacked the entire dihydrouridine (DHU) arm as in other mammaIian tRNAs (Arcari and Brownlee, 1980; de Bruijn et al., 1980; Udea et al ., 1985).

The $12 \mathrm{~S}$ and $16 \mathrm{~S}$ rRNA genes were separated by the tRNA-Val gene and were bound on their other sides by the genes for tRNA-Phe and tRNA-Leu (UUR), respectively. The sequences around the 3 ' end of the mammalian rRNA genes form a distinctive stem and loop structure (Anderson et al ., 1981, 1982; Bibb et al., 1981; Gadaleta et al., 1989). Asakawa et al. (1995) suggested that such a structure in the 12S rRNA and 16S rRNA could play an essential role in the protein synthesis and transcriptional regulation in mitochondria, respectively. The 3' contiguous region of the $12 \mathrm{~S}$ rRNA of dog mtDNA was also inferred to have a stable secondary structure, showing free energy of $-7.9 \mathrm{kcal} / \mathrm{mol}$. Although the 3 ' contiguous region of the 16S rRNA genes showed some sequence variations among mammals, it could also be fol ded into stable stem and loop structure (free energy: $-7.7 \mathrm{kcal} / \mathrm{mol}$ in the dog). The $3^{\prime}$ regions of both rRNAs of dog mtDNA showed the most stable secondary structure in comparison with other mammals.

\section{Control Region (D-Loop Region)}

The control region of dog mtDNA was 1270 bp long. However, the length of the control region was not absolute due to pronounced heteroplasmy caused by variable numbers of tandem repeats of $5^{\prime}$-GTACACGT(G/A)C-3' between CSB I and CSB II. The existence of repeat motifs in the control region and the heteroplasmy caused by variable repeats were characteristic of several mammal mtDNAs: seal, cat, pig, horse, rabbit, donkey, hedgehog, platypus, rhinoceros, and opossum. The sequence of repeat motif in dog mtDNA was similar to that of pig mtDNA (Ghivizzani, 1993), except for an A/G alteration at the 9th position of the 10-bp unit. In most mammals, the repetitive portions are located in the $3^{\prime}$ portion of the control region or between CSB I and CSB II (Wal berg and Clayton, 1981; Clayton, 1991). However, in feline mtDNA (Lopez et al.,
1996) two repetitive sequences exist, that is, RS3 between CSB I and CSB II and RS2 between tRNA-Pro and the conserved core. Also, in the control region of rabbit mtDNA (Mignotte et al., 1990), the short repeats are located between CSB I and CSB II, and the long repeats are located between tRNA-Phe and CSB III. In spite of the diversity of nucleotide sequences in the control region, a characteristic pattern of a secondary structure for the possible signaling of the start and termination of the D-loop strand has been proposed for mammals containing repetitive portions (Mignotte et al., 1990). In the control region of dog mtDNA, the 30 repeat motifs between CSB I and CSB II could also be folded into a regular, compact, and stable secondary structure with free energy of $-157.0 \mathrm{kcal} / \mathrm{mol}$ for the possible functioning in D-loop replication. Sequence similarities between repeats and the formation of secondary structures are consistent with a model of concerted evolution due to unidirectional replication slippage or unequal crossing over (Ohno, 1970; Buroker et al., 1990; Hillis et al., 1991; Wilkinson and Chapman, 1991).

\section{Untranslated Sequences}

The untranslated spacer nucleotides between the dog mitochondrial genes totaled $44 \mathrm{bp}, 12 \mathrm{bp}$ longer than those of cat. In the intervening space between the cytochrome c oxidase subunit II (COII) gene and the tRNA-Lys gene was the canine-specific "CTAGA" duplication, which was not observed in other mammals. When nucleotide sequences of the 3 '-untranslated region among mammals were compared, the mRNAs of other mammalian COII genes except for those of canine and primates had only very short 3'-untranslated regions. Ramharack and Deeley (1987) suggested that the $3^{\prime}$-untranslated regions of primate COII genes have evolved through duplication events occurring within 2-3 nucleotides following the COII translational stop codon. Also, they proposed that the $3^{\prime}$ contiguous region of primate COII mRNAs could form stable stem and loop structures immediately preceding the duplication site, thereby facilitating the mutational events involved. However, our data showed that the free energy $(-2.4 \mathrm{kcal} / \mathrm{mol})$ of the $3^{\prime}$ contiguous region of the dog COII mRNA with a 17-nt-untranslated region did not show any discrepancy with that of other mammals which had minor untranslated regions. In particular the free energy $(-10.3 \mathrm{kcal} / \mathrm{mol})$ of the $3^{\prime}$ contiguous region of the seal COII mRNA, which has only one 3 '-untranslated nucleotide, was higher than those (free energy: $-6.0 \mathrm{kcal} / \mathrm{mol}$ in human and $-4.4 \mathrm{kcal} / \mathrm{mol}$ in chimpanzee) of primate COII mRNAs. Accordingly, whether or not the presence of untranslated regions in both dog and primate sequences can be correctly attributed to the same mutational event is difficult to assess at present. 
TABLE 3

Percentage Differences of rR NAs from Pairwise Comparisons of Carnivores (Ti, Transitions; Tv, Transversions) ${ }^{a}$

\begin{tabular}{|c|c|c|c|c|c|c|c|c|c|c|c|c|c|c|c|}
\hline & \multicolumn{5}{|c|}{ Dog/seals ${ }^{b}$} & \multicolumn{5}{|c|}{ Dog/cat } & \multicolumn{5}{|c|}{ Cat/seals ${ }^{b}$} \\
\hline & Gap & $\mathrm{Ti}$ & TV & $\mathrm{Ti} / \mathrm{TV}$ & Total & Gap & $\mathrm{Ti}$ & Tv & $\mathrm{Ti} / \mathrm{TV}$ & Total & Gap & $\mathrm{Ti}$ & Tv & $\mathrm{Ti} / \mathrm{TV}$ & Total \\
\hline $12 \mathrm{~S}$ rRNA & 2.2 & 6.8 & 4.8 & 1.5 & 13.8 & 1.7 & 6.7 & 5.5 & 1.2 & 13.9 & 2.8 & 7.2 & 4.9 & 1.5 & 14.9 \\
\hline 16S rRNA & 1.4 & 6.1 & 7.5 & 0.8 & 15.0 & 2.1 & 6.5 & 6.5 & 1.0 & 15.1 & 1.5 & 6.4 & 6.2 & 1.1 & 14 \\
\hline Mean value & 1.8 & 6.5 & 6.2 & 1.2 & 14.4 & 1.9 & 6.6 & 6.0 & 1.1 & 14.5 & 2.2 & 6.9 & 5.6 & 1.3 & 14.5 \\
\hline
\end{tabular}

a Each gap was counted as a single difference.

b The rRNA genes of the dog (and cat) were compared with both the harbor seal and the grey seal and then the values were averaged.

\section{Comparison with the mtDNA of the Cat and Seal}

Besides providing details of the genome analysis of $\operatorname{dog}$ mtDNA, the purpose of this study is to document the evolutionary relationship with previously reported carnivores (the cat, the harbor seal, and the grey seal). In order to determine the relationship between the cat, the dog, and the seal, we examined the possible differences between the mtDNAs of these groups by comparing 2 rRNA and 13 protein-coding genes. The percentage differences of the two rRNA genes with respect to total difference, transition difference, and transversion difference were studied for each species-pair of dog/ seals, dog/cat, and cat/seals (see Table 3 ). In the combined sequence of the two rRNA genes, the mean of the nucleotide differences for each species-pair was 14.4, 14.5, and $14.5 \%$, respectively, showing that Transition/ Transversion ( $\mathrm{Ti} / \mathrm{Tv}$ ) ratios ranged from 1.1 to $1.3 \%$ with a mean value of $1.2 \%$. Interestingly, the dog/seals showed a higher similarity than the cat/seals in the $12 \mathrm{~S}$ rRNA gene, and vice versa in the case of the 16S rRNA gene, indicating that the phylogeny provided by only an individual rRNA gene may obscure the evolutionary relationships among carnivore species. Table 4 shows the differences and rank (in parentheses) of the total nucl eotide and the inferred amino acid sequences in the 13 protein-coding genes within each species-pair, in order of the increasing differences in each pairwise comparison. Among the three species-pairs, the range of the total nucleotide differences was $17.7-25.5 \%$ and that of total amino acid differences was $1.6-33.6 \%$. Unlike other genes, the amino acid differences (31.3\%) in the ATPase8 gene exhibited a higher mean value than the nucl eotide differences (25.2\%), showing that a considerable portion of the nucl eotide differences of this gene was related to replacement substitutions in all the species-pairs.

Among the three species-pairs, the mean values of the nucleotide differences of the 13 protein-coding genes were $21.1,21.2$, and $20.3 \%$, respectively, whereas the mean differences in the inferred amino acid sequences were $11.5,11.7$, and $11.9 \%$, revealing a noticeable discrepancy between the two modes of compari- sons. Compared with the total nucleotide differences, the amino acid differences in the protein-coding genes show a relatively good consistency for the same gene as well as being relatively insensitive to molecular saturation (Xu et al., 1996a,b). Therefore, when arranged according to the combined molecular differences for both the two rRNA genes and the inferred amino acid sequences, the order of the three species-pairs was dog/seal $<$ dog/cat $<$ cat/seal.

This study also showed that the degree of difference between carnivore mtDNAs varied according to the individual protein-coding gene applied, suggesting that the evolutionary rate of the same protein-coding gene may differ considerably between the divergences of the carnivore species. As shown in Table 4, the individual

\section{TABLE 4}

\section{Percentage Differences between the Mitochondrial Protein-Coding Genes of Carnivores ${ }^{a}$}

\begin{tabular}{|c|c|c|c|}
\hline \multirow[b]{2}{*}{ Gene } & \multicolumn{3}{|c|}{ Total nucleotide differences/amino acid differences } \\
\hline & Dog/seals ${ }^{b}$ & Dog/cat & Cat/seals ${ }^{b}$ \\
\hline $\mathrm{NADH} 1$ & (2)19.0/5.7(3) & $(1) 17.9 / 6.3(4)$ & (1)15.8/7.7(5) \\
\hline $\mathrm{NADH} 2$ & $(11 / 12) 23.6 / 18.9(7)$ & (12)23.7/22.2(12) & (11) $22.8 / 23.1(12)$ \\
\hline $\mathrm{COI}$ & (6) $20.1 / 2.5(1)$ & (3) $19.5 / 2.5(1)$ & (3) $18.3 / 1.6(1)$ \\
\hline $\mathrm{COII}$ & (1)17.7/4.2(2) & $(4 / 5) 19.7 / 4.0(2)$ & (4)18.6/3.8(2) \\
\hline ATPase8 & (13)25.5/33.6(13) & (13)25.0/31.3(13) & (13)25.0/29.1(13) \\
\hline ATPase6 & (5)20.0/8.0(5) & $(8 / 9) 21.6 / 9.7(6)$ & $(7 / 8) 20.3 / 8.0(6)$ \\
\hline COIII & (8)20.8/7.5(4) & (2)19.2/5.0(3) & (2)17.9/6.3(3) \\
\hline NADH3 & (7)20.6/12.2(11) & $(8 / 9) 21.6 / 11.3(8)$ & (6)20.2/11.8(8) \\
\hline NADH4L & (10)22.8/8.2(6) & (7)21.2/8.2(5) & (9)20.9/6.15(4) \\
\hline NADH4 & (3)19.7/9.5(8) & (11)23.3/11.5(9) & (10)21.7/12.0(9) \\
\hline NADH5 & $(11 / 12) 23.6 / 16.7(12)$ & (10)22.1/16.7(11) & (12)23.9/18.4(11) \\
\hline NADH 6 & (9)20.8/11.4(10) & (4/5)19.7/12.6(10) & $(7 / 8) 20.3 / 15.7(10)$ \\
\hline $\begin{array}{l}\text { Cyto- } \\
\text { chromeb }\end{array}$ & (4)19.8/11.2(9) & (6)21.1/10.3(7) & (5)19.4/10.5(7) \\
\hline Mean & & & \\
\hline value & 21.1/11.5 & $21.2 / 11.7$ & 20.3/11.9 \\
\hline
\end{tabular}

a Figures in parentheses show the position with respect to the increasing difference in each mode of comparison.

$\mathrm{b}$ The protein-coding genes of the dog (and cat) were compared with both the harbor seal and the grey seal and then the values were averaged. 
genes exhibited a somewhat inconsistent ranking position both in modes of comparison as well as in different species-pairs; in particular, the positions of the COIII and NADH 4 genes showed a conspicuous inconsistency in the total nucleotide difference within different speciespairs. This inconsistency for the same gene, as discussed by Xu et al. (1996a), was more pronounced in comparisons based on the total nucleotide differences than on the amino acid differences.

The mitochondrial cytochrome b genehas been generally used for the documentation of evolutionary relationships between several mammals (Irwin et al., 1991; Arnason and Gullberg, 1996). The conservative nucleotide substitutions of the cytochrome b gene, as reviewed by Arnason and Gullberg (1996), have provided results that are consistent with accepted phylogenetic relationships spanning a wide temporal range. The comparison of the cytochrome $b$ gene among the three carnivore species-pairs is summarized in Table 5. The mean of the conservative differences between the three carnivore species was $11 \%$. With respect to the conservative differences of the cytochrome $b$ gene, a closer relationship between the dog and the seal was also notable. As is evident in Table 5, the Ti/Tv ratios of the third codon position within all species-pairs showed a very low value (mean value of 1.1 ) in comparison to those (mean value of 13.0) within the closely related species-pairs previously studied (Xu et al., 1996a), suggesting that transitional saturation was pronounced among carnivore species. Therefore, as mentioned earlier, total nucleotide differences may cause considerable error in the estimation of the evolutionary separation among distantly related species.

In our data the $12 \mathrm{~S}$ rRNA differences were in line with the amino acid differences, whereas the 16S rRNA differences conformed to the total nucleotide differences of the protein-coding genes. The total percentage differences between the tRNA genes within each speciespair of dog/seals, dog/cat, and cat/seals were 13.4, 12.5, and $13.8 \%$, respectively, showing lower difference val-

\section{TABLE 5}

\section{Comparison of the Cytochrome b Gene in Three Carnivore Species-Pairs ${ }^{a}$}

\begin{tabular}{lccc}
\hline & Dog/seals & Dog/cat & Cat/seals \\
\hline Percentage nt difference & 19.8 & 21.1 & 19.4 \\
Percentage cons. nt difference & 10.5 & 11.3 & 11.2 \\
Percentage aa difference & 11.2 & 10.3 & 10.5 \\
Ratio nt substitution & $2.8 / 1.0 / 9.6$ & $2.7 / 1.0 / 9.6$ & $2.7 / 1.0 / 12.1$ \\
Ratio cons. nt substitution & $1.8 / 1.0 / 4.3$ & $1.7 / 1.0 / 4.5$ & $2 / 1.0 / 6.2$ \\
Ratio 3rd codon pos. Ti/TV & 1.26 & 1.14 & 0.95 \\
\hline
\end{tabular}

a Cons. (conservative) difference defined as all nonsynonymous nucleotide substitutions in the first codon position, all substitutions in the second codon position, and transversions in the third codon position. nt, nucleotide; aa, amino acid. ues than those of the rRNA genes in all the speciespairs.

\section{The Phylogenetic Position of the Dog among}

FerungulateTaxa

As mentioned in the Introduction, the phylogenetic relationships among mammalian orders based on the combined sequences of mtDNA protein-coding genes are well established. Phylogenetic analyses have grouped Carnivora, Perissodactyla, and Artidodactyla (+Cetacea) into a superordinal clade (as a group Ferungulata). In the present study the phylogenetic position of the dog relative to seven other mammalian species (six Ferungulate taxa and one rodent as an outgroup) was addressed based on the concatenated sequences of 12 protein-coding genes encoded by their mitochondrial genome. The NADH6 gene was not included as it is encoded on a different strand relative to the remaining 12 protein-coding genes. For the tree reconstruction, the maximum likelihood analysis of PUZZLE program (Strimmer and Haeseler, 1996) was accomplished. In this analysis, as a model of amino acid substitution the mtREV24 (Adachi and Hasegawa, 1996) was used, and uniform rate over all sites was assumed. The phylogenetic tree based on a maximum likelihood analysis is shown in Fig. 1. The reliability value of quartet puzzling for the internal branches of the tree topology is shown as a percentage and the Carnivora branches are designated with lowercase letters (a-c). A clade (branch a) comprising the Carnivora group (cat, dog, and seals) is supported by a reliability value of $100 \%$. The phylogenetic analysis showed the clade (branch b) separating the dog and the seals from the cat, supporting our data based on the molecular studies of mtDNA between the cat, the dog, and the seal. Also, the phylogenetic analysis supported a sister group relationship between Carnivora and Perissodactyla. By supplementing the carnivore group with an additional dog sequence, the present maximum likelihood topol ogy resolves the relationship of the carnivore species as well as recapitulating the results of the previous phylogenetic relationship (Xu et al., 1996b; Penny and Hasegawa, 1997; Arnason et al., 1997).

\section{The Dating of the Evol uti onary Divergence within the} CarnivoreSpecies

Among the carnivore species, evolutionary divergence based on the molecular study of mtDNA is relatively unknown, although several molecular techniques, such as protein electrophoresis, DN A hybridization, and microcomplement fixation, have been used to reconstruct phylogenetic relationships and to estimate divergence time (Wayne et al., 1991).

Recently, phylogenetic analyses based on a concatenated sequence of the inferred amino acid of proteincoding mtDNA genes have contributed to establish reliable phylogenetic relationships between mamma- 


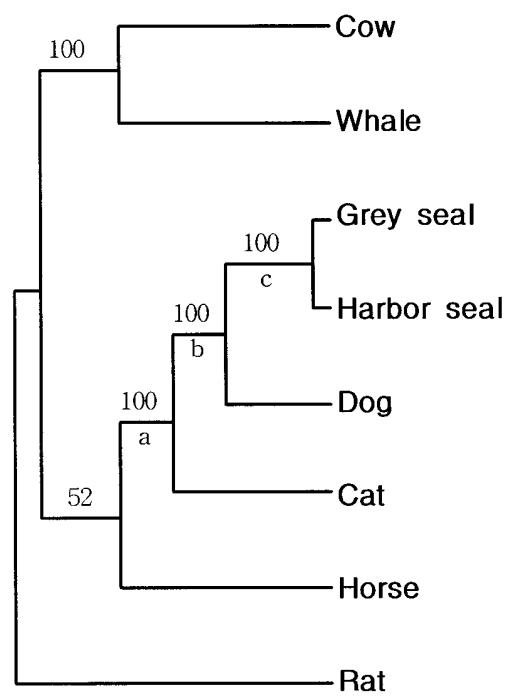

FIG. 1. Phylogenetic position of the dog relative to seven other mammalian species (six ferungulate taxa and one rodent), based on 12 proteins encoded by their mitochondrial genome. All mitochondrial genomes are available in the GenBank database: cat (U20753), harbor seal (X63726), grey seal (X72004), cow (J 01394), fin whale (X61145), horse (X79547), and rat (X14848). The maximum likelihood method of PUZZLE Version 4.0 (Strimmer and Haeseler, 1996) was used to reconstruct the phylogenetic tree from the concatenated amino acid sequences of protein-coding genes, except for NADH 6 which is encoded on a different strand relative to the remaining 12 protein coding genes. As a model of amino acid substitution the mtREV24 (Adachi and Hasegawa, 1996) was used, and as a model of rate heterogeneity uniform rate over all sites was taken into account. For robustness of the tree, the analysis was accomplished using 1000 puzzling steps. The reliability value of quartet puzzling for the internal branches of the tree topology is shown as a percentage.

lian orders. Also, as discussed earlier, the analyses on the basis of the conservative nucleotide differences of the cytochrome $b$ gene have generally been in good agreement with accepted phylogeny. Accordingly, the differences of a concatenated amino acid sequence of protein-coding genes and the differences of the conservative nucleotide of the cytochrome b gene have made it possible to propose a date for the evolutionary separation between the cat, the dog, and the seal .

The genetic distances between the eight mammalian species based on the concatenated amino acid sequence of 12 protein-coding mtDNA genes are given in Table 6. By applying, as a reference, a divergence time of 60 million years ago (MYA) for artidodactyls and cetaceans (Arnason and Gullberg, 1996), the values in Table 6 suggest that the evolutionary divergences within each species-pair of dog/seal, dog/cat, and cat/ seal were dated to 44,46 , and 47 MYA, respectively. In addition, based on the differences of the conservative nucleotide of the cytochrome $b$ gene (Table 5), the evolutionary divergences within above carnivore species were dated to approximately $50 \sim 54$ MYA.

In this study, the differences of the concatenated amino acid sequences as well as the differences of the conservative nucleotide of the cytochrome b gene showed similar values within each species-pair, showing mean values of $11.7 \%$ and $11.0 \%$, respectively. Also, the phylogenetic topology showed that the carnivore species formed a clade, sharing a common ancestor. Therefore, there is no reason to attempt to discriminate absolutely the divergence time of the cat/dog/seal. In the present study, the molecular differences of the mtDNA indicate that the cat, the dog, and the seal had a common ancestor $50 \pm 4$ MYA.

\section{DISCUSSION}

The genome organization, gene contents, and codon usage of the dog mitochondrial genome conformed to those of other mammalian mitochondrial genomes, except for the "CTAGA" duplication events following the translational stop codon of the COII gene. As mentioned in the Introduction, the evolutionary relationships between carnivore species, based on the comparison of complete mtDNA, have so far been limited due to the paucity of data. The present inclusion of the complete sequences of dog mtDNA have

TABLE 6

Genetic Distances Based on Amino Acid Differences between Eight Mammalian Speciesa

\begin{tabular}{|c|c|c|c|c|c|c|c|c|}
\hline & Cow & Whale & Seal (G) & Seal $(H)$ & Dog & Cat & Horse & Rat \\
\hline Cow & 0.00000 & & & & & & & \\
\hline Whale & 0.15462 & 0.00000 & & & & & & \\
\hline Seal (G) & 0.15912 & 0.19541 & 0.00000 & & & & & \\
\hline Seal $(H)$ & 0.15451 & 0.19371 & 0.01589 & 0.00000 & & & & \\
\hline Dog & 0.15623 & 0.20172 & 0.11399 & 0.11318 & 0.00000 & & & \\
\hline Cat & 0.14930 & 0.19725 & 0.12109 & 0.12020 & 0.11790 & 0.00000 & & \\
\hline Horse & 0.13409 & 0.17155 & 0.14517 & 0.14486 & 0.13839 & 0.13336 & 0.00000 & \\
\hline Rat & 0.29314 & 0.31965 & 0.30257 & 0.30092 & 0.29510 & 0.28529 & 0.28538 & 0.00000 \\
\hline
\end{tabular}

a Order: Artidodactyla (cow), Cetacea (fin whale), Carnivora (Grey (G) seal, Harbor (H) seal, dog, cat), Perissodactyla (horse), Rodentia (rat). Distance values were obtained from the maximum likelihood distances of the PUZZLE program (Strimmer and Haeseler, 1996) based on a comparison of the concatenated amino acid sequences (3627 aa) of 12 protein-coding mtDNA genes. 
made it possible to address the relationships between carnivore species. The combined molecular differences, in two rRN A genes as well as in the inferred amino acid sequences of the mitochondrial 13 protein-coding genes, would suggest that there is a closer relationship between the dog and the seal than there is between either of these species and the cat. Our data support the previous morphological data that indicate a main split between Feliodea (cats) and Canoidea (dogs/seals). This study also showed that the evolutionary rates provided by an individual mtDNA gene may differ quite considerably, suggesting that the evolutionary relationship of distantly related species should be examined with caution unless supported with sufficient sequence data and/or a comprehensive representation of taxa. The different patterns characterizing the individual proteincoding gene in a pairwise comparison of carnivore species support the previous reports (Arnason et al., 1993; Cao et al., 1994; Xu et al., 1996a) that the same protein-coding gene may show different evolutionary rates in different pairwise comparisons, making it difficult to establish a general evolutionary relationship from each gene on its own.

The availability of mtDNA molecules of the dog and other carnivore species (cat and seal) made it possible to propose the dating of the evolutionary separation of these groups on the basis of complete mtDN A data. The proposed dating of the divergence between the cat, the dog, and the seal, at $50 \pm 4$ MYA, conformed to the estimates of Wayne et al. (1991) who placed the maximum divergence date of the Carnivora species at around 55 million years based on a protein electrophoresis and DNA hybridization. Also, the dating was in line with the divergence time (approximately $50 \pm 5$ MYA) based on the transversion rates of the 12S rRNA gene which has been found to correlate with time (Arnason and J ohnsson, 1992). However, the dating was not consistent with divergence dates from fossil records. The fossil records which estimate the divergence time of the Carnivora species are relatively plentiful and have been well studied. Most paleontological evidence suggests that the divergence time of the Carnivora species is no ol der than 40 MYA. The paleontological record of Canidae was traceable to 32-35 MYA (Savage and Russell, 1983), and the earliest divergence of Felidae in fossil records was estimated at 35-40 MYA (Radinsky, 1975; Hunt, 1989). Also, the fossil records placed the divergence time of Pinnipedia at 27-30 MYA (Berta et al., 1989). However, generally paleontological records grossly underestimate the age of evolutionary divergences. As discussed by Xu et al . (1996b), although fossil records are reasonably complete and correctly estimated, the time of evolutionary separation should be estimated before the development of morphological traits that can be recognized among fossil finds. The present molecular analysis suggests that the age of Carnivora fossils falls well within the dating of the carnivore separation. The dog, C. familiaris, is one of the oldest domesticated animals and one of the most familiar to man. In recent times, dogs have been a common focus for research concerning their evolution and origin (Roy et al., 1994; Vila et al., 1997). Accordingly, the full sequence of dog mtDNA will be useful for the further study of the evolution and genetics of the canine species as well as for the documentation of the phylogenetic position of the dog among mammalian orders.

\section{ACKNOWLEDG MENT}

We thank the Korea Science and Engineering F oundation for their financial support.

\section{REFERENCES}

Adachi, J ., and Hasegawa, M. (1996). Model of amino acid substitution in proteins encoded by mitochondrial DNA. J . Mol. Evol. 42: 459-468.

Anderson, S., Bankier, A. T., Barrell, B. G., de Bruijn, M. H. L., Coulson, A. R., Drouin, J ., Eperron, I. C., Nierlich, D. P., Roe, B. A., Sanger, F. A., Schreier, P. H., Smith, A. J . H., Staden, R., and Young, I. G. (1981). Sequence and organization of the human mitochondrial genome. Nature 290: 457-465.

Anderson, S., de Bruijn, M. H. L., Coulson, A. R., Eperson, I. C., Sanger, F., and Young, I. G. (1982). The complete sequence of bovine mitochondrial DNA; Conserved features of the mammalian mitochondrial genomes. J . Mol. Biol. 156: 683-717.

Aquadro, C. F., and Greenberg, B. D. (1983). Human mitochondrial DNA variation and evolution: Analysis of nucleotide sequences from seven individuals. Genetics 103: 287-312.

Arcari, P., and Brownlee, G. G. (1980). The nucleotide sequence of a small (3S) seryl-tRNA (anticodon GCU) from beef heart mitochondria. Nucleic Acids Res. 8: 5207-5212.

Arnason, U., and Gullberg, A. (1993). Comparison between the complete mtDNA sequences of the blue and the fin whale, two species that can hybridize in nature. J . Mol. Evol. 37: 312-322.

Arnason, U., and Gullberg, A. (1996). Cytochrome b nucleotide sequences and the identification of five primary lineages of extant cetaceans. Mol. Biol. Evol. 13: 407-417.

Arnason, U., Gullberg, A., and J anke, A. (1997). Phylogenic analyses of mitochondrial DNA suggest a sister group relationship between Xenarthra (Edentata) and Ferungulates. Mol. Biol. Evol. 14: 762-768.

Arnason, U., Gullberg, A., J ohnsson, E., and Ledje, C. (1993). The nucleotide sequence of the mitochondrial DNA molecule of the grey seal, Halichoerus grypus, and comparison with mitochondrial sequences of other true seals. J. Mol. Evol. 37: 323-330.

Arnason, U., Gullberg, A., and Widegren, B. (1991). The complete nucleotide sequence of the mitochondrial DNA of the fin whale, Balaenoptera physalus. J . Mol. Evol. 33: 556-568.

Arnason, U., and J ohnsson, E. (1992). The complete mitochondrial DNA sequence of the harbor seal, Phoca vitulina. J . Mol. Evol. 34: 493-505.

Asakawa, S., Himeno, H., Miura, K., and Watanabe, K. (1995). Nucleotide sequence and gene organization of the starfish Asterina pectinifera mitochondrial genome. Genetics 140: 1047-1060.

Attardy, G. (1985). Animal mitochondrial DNA: An extreme example of genetic economy. Int. Rev. Cytol . 93: 93-145.

Avise, J . C. (1994). “Molecular Markers: Natural History and Evolution." Chapman and Hall, New York. 
Bairoch, A. (1992). PC/GENE software program. University of Geneva. [IntelliGenetics Inc. Release 6.70]

Berta, A., Ray, C. E., and Wyss, A. R. (1989). Skeleton of the oldest known pinniped, Enaliarctos mealsi. Science 244: 60-62.

Bibb, M. J ., Van Etten, R. A., Wright, C. T., Walberg, M. W., and Clayton, D. A. (1981). Sequence and gene organization of mouse mitochondrial DNA. Cell 26: 167-180.

Brown, J . R., Beckenbach, A. T., and Smith, M.J . (1993). Intraspecific DNA sequence variation of the mitochondrial control region of White Sturgeon (Acipenser transmontanus). Mol. Biol. Evol. 10: 326-341.

Buroker, N. E., Brown, J . R., Gilbert, T. A., O'hara, P. J ., Beckenbach, A. T., Thomas, W. K., and Smith, M.J . (1990). Length heteroplasmy of sturgeon mitochondrial DNA: An illegitimate elongation model. Genetics 124: 157-163.

Cao, Y., Adachi, J ., J anke, A., Paabo, S., and Hasegawa, M. (1994). Phylogenetic relationships among eutherian orders estimated from inferred sequences of mitochondrial proteins: Instability of tree based on a single gene. J . Mol. Evol. 39: 519-527.

Cedegren, R. J ., Sankoff, D., Larue, B., and Grosjean, H. (1981). The evolving tRNA molecule. CRC Crit. Rev. Biochem. 11: 35-104.

Charlesworth, B., Sniegowski, P., and Stephan, W. (1994). The evolutionary dynamics of repetitive DNA in eukaryotes. Nature 371: 215-220.

Clary, D. O., and Wolstenholme, D. R. (1985). The mitochondrial DNA molecule of Drosophila yakuba: Nucleotide sequence, gene organization, and genetic code. J. Mol. Evol. 22: 252-271.

Clayton, D. A. (1991). Replication and transcription of vertebrate mitochondrial DNA. Annu. Rev. Cell Biol. 7: 453-478.

de Bruijn, M. H. L., Schreier, P., Eperon, I. C., Barrell, B. G., Chen, E. Y., Armstrong, P. W., Wong, J. F. H., and Roe, B. A. (1980). A mammalian mitochondrial serine transfer RNA lacking the "dihydrouridine" loop and stem. Nucleic Acids Res. 8: 5213-5222.

D'Erchia, A. M., Gissi, C., Pesole, G., Saccone, C., and Arnason, U. (1996). The guinea-pig is not a rodent. Nature 381: 597-600.

Desjardins, P., and Morais, R. (1990). Sequence and gene organization of the chicken mitochondrial genome. J. Mol. Biol. 212: 599-634.

Gadaleta, G., Pete, G., de Candia, G., Quagliariello, C., Sibisa, E., and Saccone, C. (1989). The complete nucleotide sequence of the Rattus norvegicus mitochondrial genome: Cryptic signals revealed by comparative analysis between vertebrates. J . Mol. Evol. 28: 497516.

Ghivizzani, S. C., Mackay, S. L. D., Madsen, C. S., Laipis, P. J ., and Hauswirth, W. W. (1993). Transcribed heteroplasmic repeated sequences in the porcine mitochondrial DNA D-loop region. J . Mol. Evol. 37: 36-47.

Hillis, D. M., Moritz, C., Porter, C. A., and Baker, R. J . (1991). Evidence for biased gene conversion in concerted evolution of ribosomal DNA. Science 251: 308-310.

Horai, S., Hayasaka, K., Kondo, R., Tsugane, K., and Takahata, N. (1995). Recent African origin of modern humans revealed by complete sequences of hominoid mitochondrial DNAs. Proc. Natl. Acad. Sci. USA 92: 532-536.

Hunt, R. M. (1989). Evolution of the Aeleuroid Carnivora: significance of the vental promontorial process of the petrosal, and the origin of basicranial patterns in the living families. Am. Museum Novitates 2930: 1-32.

Irwin, D. M., Kocher, T. D., and Wilson, A. C. (1991). Evolution of the cytochrome b gene of mammals. J . Mol. Evol . 32: 128-144.

J anczewski, D. N., Modi, W. S., Stephens, J . C., and O'Brien, S. J . (1995). Molecular evolution of mitochondrial 12S RNA and cytochrome b sequences in the pantherine lineage of Felidae. Mol. Biol. Evol. 12: 690-707.

J anke, A., Feldmaier-Fuchs, G., Kelly Thomas, W., von Haeseler, A., and Paabo, S. (1994). The marsupial mitochondrial genomeand the evolution of placental mammals. Genetics 137: 243-256.

J anke, A., Gemmell, N.J ., Feldmaier-Fuchs, G., von Haeseler, A., and Paabo, S. (1996). The mitochondrial genome of a monotreme-The platypus (Ornithorhynchus anatinus). J . Mol. Evol . 42: 153-159.

J anke, A., Xu, X., and Arnason, U. (1997). The complete mitochondrial genome of the wallaroo (Macropus robustus) and the phylogenetic relationship among Monotremata, Marsupialia, and Eutheria. Proc. Natl. Acad. Sci. USA 94: 1276-1281.

Kocher, T. D., Thomas, W. K., Meyer, A., Edwards, S. V., Paabo, S., Villablanca, F. X., and Wilson, A. C. (1989). Dynamics of mitochondrial DNA evolution in animals: Amplification and sequencing with conserved primers. Proc. Natl. Acad. Sci. USA 86: 6196-6200.

Krettek, A., Gullberg, A., and Arnason, U. (1995). Sequence analysis of the complete mitochondrial DNA molecule of the hedgehog, Erinaseus europaeus, and the phylogenetic position of the Lipotyphla. J . Mol. Evol. 41: 952-957.

Kumazawa, Y., and Nishida, M. (1993). Sequence evolution of mitochondrial tRNA genes and deep-branch animal phylogenetics. J . Mol. Evol. 37: 380-398.

Lansman, R. A., Shade, R. O., Shapira, J . F., and Avise, J . C. (1981). The use of restriction endonucleases to measure mitochondrial DNA sequence relatedness in natural populations. III. Techniques and potential applications. J . Mol. Evol. 17: 214-226.

Li, W. H., and Graur, D. (1991). "Fundamentals of Molecular Evolution." Sinauer, Sunderland, MA.

Lopez, J. V., Cevario, S., and O'Brien, S. J. (1996). Complete nucleotide sequences of the Domestic cat (Felis catus) mitochondrial genome and a transposed mtDNA tandem repeat (Numt) in the nuclear genome. Genomics 33: 229-246.

Mignotte, F., Gueride, M., Champagne, A. M., and Mounolou, J . C. (1990). Direct repeats in the non-coding region of rabbit mitochondrial DNA: Involvement in the generation of intra- and interindividual heterogeneity. Eur. J . Biochem. 194: 561-571.

Morin, P. A., Moore, J . J ., Chakraborty, R., J in, L., Goodall, J ., and Woodruff, D. S. (1994). Kin Selection, Social Structure, Gene Flow, and the Evolution of Chimpanzees. Science 265: 1193-1201.

O'Brien, S. J . (1994a). Genetic and phylogenetic analyses of endangered species. Annu. Rev. Genet. 28: 467-489.

O'Brien, S. J. (1994b). A role for molecular genetics in biological conservation. Proc. Natl. Acad. Sci. USA 91: 5748-5755.

Ohno, S. (1970). “Evolution by Gene Duplication." Springer Verlag, Berlin.

Okimoto, R., Macfarlane, J . L., Clary, D. O., and Wolstenholme, D. R. (1992). The mitochondrial genomes of two nematodes, Caenorhabditis el egans and Ascaris suum. Genetics 130: 471-498.

Pecon, S., J ohnson, W. E., Goldman, N. D., and O’Brien, S. J . (1994). Phylogenetic reconstruction of south American felids defined by protein electrophoresis. J . Mol. Evol. 39: 296-305.

Penny, D., and Hasegawa, M. (1997). The platypus put in its place. Nature 387: 549-550.

Radinsky, L. (1975). Evolution of the felid brain. Brain Behav. Evol. 11: 214-254.

Ramharack, R., and Deeley, R. G. (1987). Structure and evolution of primate cytochrome c oxidase subunit II gene. J . Biol. Chem. 262: 14014-14021.

Roy, M. S., Geffen, E., Smith, D., Ostrander, E. A., and Wayne, R. K. (1994). Patterns of differentiation and hybridization in north American wolflike canids, revealed by analysis of microsatellite loci. Mol. Biol. Evol. 11: 553-570.

Ruvulo, M., Zehr, S., Dornum, M. V., Pan, D., Chang, B., and Lin, J . (1993). Mitochondrial COII sequences and modern human origins. Mol. Biol. Evol. 10: 1115-1135.

Sanger, F., Nichlen, S., and Coulson, A. R. (1977). DNA sequencing 
with chain-terminating inhibitors. Proc. Natl. Acad. Sci. USA 74: 5463-5467.

Savage, D. E., and Russell, D. E. (1983). “Mammalian Paleofaunas of the World."Addison Wesley, London.

Strimmer, K., and von Haeseler, A. (1996). Quartet puzzling: A quartet maximum likel ihood method for reconstructing treetopologies. Mol. Biol. Evol. 13: 964-969.

Udea, T., Ohta, T., and Watanabe, K. (1985). Large scale isolation and some properties of AGY-specific serine tRNA from bovine heart mitochondria. J . Biochem. 98: 1275-1284.

Vila, C., Savolainen, P., Maldonado, J . E., Amorim, I. R., Rice, J . E., Honeycutt, R. L., Crandall, K. A., Lundeberg, J ., and Wayne, R. K. (1997). Multiple and ancient origins of the domestic dog. Science 276: 1687-1689.

Wal berg, M. W., and Clayton, D. A. (1981). Sequence and properties of human KB cell and the mouse $L$ cell $D$-loop regions of mitochondrial DNA. Nucleic Acids Res. 9: 5411-5421.

Wayne, R. K., Van Valkenburgh, B., and O'Brien, S. J. (1991). Molecular distance and divergence time in carnivores and primates. Mol. Biol. Evol. 8: 297-319.

Wilkinson, G. S., and Chapman, A. M. (1991). Length and sequence variation in evening bat D-Ioop mtDNA. Genetics 128: 607-617.

Wolstenholme, D. R., Macfarlane, J . L., Okimoto, R., Clary, D. O., and Wahleithner, J . A. (1987). Bizarre tRNAs inferrd from DNA se- quences of mitochondrial genomes nematode worms. Proc. Natl. Acad. Sci. USA 84: 1324-1328.

Xu, X., and Arnason, U. (1994). The complete mitochondrial DNA sequence of the horse, Equus caballus: Extensive heteroplasmy of the control region. Gene 148: 357-362.

Xu, X., and Arnason, U. (1996). The mitochondrial DNA molecule of sumatran orangutan and a molecular proposal for two (Bornean and Sumatran) species of orangutan. J. Mol. Evol . 43: 431-437.

Xu, X., and Arnason, U. (1997). The complete mitochondrial DNA sequence of the white rhinoceros, Ceratotherium simum, and comparison with the mtDNA sequence of the Indian rhinoceros, Rhinoceros unicornis. Mol. Phylogenet. Evol. 7: 189-194.

Xu, X., Gullberg, A., and Arnason, U. (1996a). The complete mitochondrial DNA (mt DNA) of the donkey and mtDNA comparisons among four closely related mammalian species-pairs. J. Mol. Evol. 43: 438-446.

Xu, X., J anke, A., and Arnason, U. (1996b). The complete mitochondrial DNA sequence of the greater Indian rhinoceros, Rhinoceros unicornis, and the phylogenetic relationship among Carnivora, Perissodactyla, and Artiodactyla (+Cetacea). Mol. Biol. Evol. 13: 1167-1173.

Zimmerman, E. G., Atkins, D. R., Planz, J . V., and Schurr, M. J . (1988). A rapid procedure for isolation of mitochondrial DNA. Gene Anal. Techn. 5: 102-104. 